\title{
ÍNDICE COMPOSTO DE SUSTENTABILIDADE NA AGRICULTURA: UMA APLICAÇÃO DO MÉTODO TOPSIS
}

\author{
Composite Sustainability Index In Agriculture: An Application Of The Topsis Method
}

\begin{abstract}
RESUMO
Este trabalho tem como objetivo estimar um índice composto de sustentabilidade para os produtores de frutas, verduras e legumes da microrregião de Toledo, Paraná (PR). Realizou-se uma pesquisa descritiva, de levantamento, com aplicação de questionários, de cunho quantitativo. Utilizando a metodologia Technique for Order Preference by Similarity to Ideal Solutions (TOPSIS), buscou-se agregar 16 indicadores simples de sustentabilidade em três indicadores compostos de sustentabilidade, correspondentes às dimensões econômica, social e ambiental da sustentabilidade, e um índice composto total de sustentabilidade para os produtores da microrregião. A amostra do estudo constituiu-se de 99 produtores agrícolas de frutas, verduras e legumes da referida microrregião, que responderam voluntariamente ao instrumento de pesquisa proposto. Após a análise dos resultados encontrados, verificou-se que há similaridade entre os indicadores compostos das dimensões da sustentabilidade, podendo-se conjecturar que não há nível de sustentabilidade maior em nenhuma das dimensões. De acordo com a metodologia TOPSIS, verificou-se também que o índice composto de sustentabilidade total dos produtores rurais da microrregião está mais distante de uma situação ideal de sustentabilidade e mais próximo de uma situação não ideal, conclusão que se estende para os indicadores compostos das dimensões. Neste sentido, este trabalho contribui como informação diagnóstica, para todos os agentes envolvidos com o setor, em especial para os produtores agrícolas, apresentando aspectos que podem ser abordados por estratégias alternativas com propósito de aumentar o nível de sustentabilidade agrícola na microrregião.
\end{abstract}

Leandro Pereira dos Santos

Instituto Federal do Paraná

leandro.santos@ifpr.edu.br

Carla Maria Schmidt

Universidade Estadual do Oeste do Paraná

carlamariaschmidt@hotmail.com

Recebido em: 03/10/2019. Aprovado em: 13/03/2020

Avaliado pelo sistema double blind review

Avaliador científico: Eduardo César Silva

DOI: $10.48142 / 2220201515$

\begin{abstract}
This paper aims to estimate a composite sustainability index for fruit and vegetable producers in the micro-region of Toledo, Paraná (PR). A descriptive research was carried out, survey, with the application of questionnaires, of quantitative nature. Using the Technique for Order Preference by Similarity to Ideal Solutions (TOPSIS) methodology, we seek to aggregate 16 simple sustainability indicators into three composite sustainability indicators, corresponding to the economic, social, and environmental dimensions of sustainability, as well as a total composite index sustainability for micro-region producers. The study sample consisted of 99 agricultural producers of fruits and vegetables from the said micro-region, who voluntarily responded to the proposed research instrument. After analyzing the results found, it was found that there is similarity between the indicators composed of the dimensions of sustainability, and it can be conjectured that there is no higher level of sustainability in any of the dimensions. According to the TOPSIS methodology, it was also found that the composite index of total sustainability of rural producers in the micro-region is farther from an ideal situation of sustainability and closer to a non-ideal situation, a conclusion that extends to the indicators composed of dimensions. In this sense, this work contributes as diagnostic information, for all agents involved with the sector, especially for agricultural producers, presenting aspects that can be addressed by alternative strategies with the purpose of increasing the level of agricultural sustainability in the micro-region.
\end{abstract}

Palavras-chave: Alimentos; Microrregião de Toledo-PR; Metodologia.

Keywords: Foods; Microregion of Toledo-PR; Methodology.

\section{INTRODUÇÃO}

A produção de alimentos, de acordo com Guedes, Torres e Campos (2014) é um tema estratégico tanto no contexto nacional, como no mundial. Por esta razão, demanda constante reflexão e discussão, principalmente quanto aos elementos necessários para a sustentação da produção a longo prazo, abordando as esferas econômica, ambiental e social da geração presente, sem danificar o suprimento das futuras gerações. Segundo os autores, esta temática se torna ainda mais importante no Brasil, que exerce papel relevante na produção e exportação de alimentos, com expressiva responsabilidade para com o suprimento alimentar global. No contexto da importância da produção de alimentos no Brasil, Reifschneider e 
Lopes (2015) abordam que o país possui uma população predominantemente urbana, com projeção de atingir 212 milhões de habitantes em 2025, com consequente aumento da demanda por alimentos, o que sugere a oportunidade para o desenvolvimento de uma horticultura mais sustentável.

A respeito do suprimento de alimentos, Lutz, Sanderson e Scherbov (2001) destacam que este é influenciado, no Brasil e no mundo, pelo lado da demanda, por diversos fatores de natureza demográfica e econômica. Com relação aos elementos demográficos, destaca-se o aumento populacional, principalmente nos países desenvolvidos, associado ao processo de urbanização pelo qual o mundo vem passando. Segundo a FAO (2019), em 2050 a população urbana passará dos $50 \%$ atuais para quase $70 \%$. No Brasil, de acordo com o Censo Populacional do IBGE de 2010, dos atuais $86 \%$ da população urbana, em 2030 esta população deve passar para mais de $90 \%$ e, em 2050, deve chegar a 94\% (IBGE, 2013). No que diz respeito aos elementos econômicos, destaque deve ser dado ao aumento da renda per capita nos países emergentes e em desenvolvimento (HAWKSWORTH; CHAN, 2013). As mudanças nos padrões de consumo, oriundos da melhoria na renda ou mesmo dos hábitos de consumo também poderão resultar em maior demanda de alguns produtos, dentre estes, frutas e vegetais, com ênfase aos produtos de maior qualidade (GUEDES; TORRES; CAMPOS, 2014).

Pelo lado da oferta, os principais elementos que devem influenciar o suprimento de alimentos dizem respeito à redução da disponibilidade de água e terra agriculturável, à ciência, tecnologia e inovação na agropecuária, às mudanças climáticas, à degradação dos solos, ao uso industrial da água e à utilização da terra para a produção de biocombustíveis. Mais especificamente no Brasil, o sistema agroalimentar deve sofrer influência de elementos como a composição do setor produtivo, formado principalmente pela pequena produção ou pela grande empresa agrícola, a redução de mão de obra qualificada disponível na agricultura, entre outros (GUEDES; TORRES; CAMPOS, 2014).

Considerando a relevância da sustentabilidade na agricultura e a necessidade de ampliar a discussão sobre o tema, este trabalho tem a seguinte questão problema: é possível estimar um índice composto de sustentabilidade para os produtores de frutas, verduras e legumes na microrregião de Toledo, PR? Nesta perspectiva, este trabalho tem como objetivo estimar um índice composto de sustentabilidade para os produtores de frutas, verduras e legumes da microrregião de Toledo, PR. Utilizando a metodologia TOPSIS, busca-se agregar 16 indicadores simples de sustentabilidade em três indicadores compostos de sustentabilidade, correspondentes às dimensões econômica, social e ambiental da sustentabilidade, e também um índice composto total de sustentabilidade para os produtores da microrregião. Indicadores compostos são construídos a partir da compilação de indicadores individuais (ou simples), obedecendo à alguma metodologia implícita. Idealmente, o indicador composto deve medir aspectos multidimensionais, que não poderiam ser capturados por um único indicador simples, como por exemplo, a sustentabilidade (JRC-EC, 2008).

Fallah-Alipour et al. (2018), no contexto do necessário aumento da sustentabilidade na agricultura, destacam a importância da difusão de abordagens utilizadas na construção de indicadores, bem como de formas de agregação e simplificação destes, para uma correta avaliação da realidade empírica da sustentabilidade na agricultura. Latrufe et al. (2016) chamam a atenção para a definição, princípios e avaliação da sustentabilidade na agricultura, aspectos nos quais os indicadores têm papel fundamental. Nesta perspectiva, o presente trabalho se revela importante com seu possível aporte para a temática sobre indicadores de sustentabilidade na agricultura.

A importância da contribuição do estudo se reforça uma vez que essa categoria de indicadores tem sido reconhecida como importante ferramenta para diagnósticos, análise de políticas, estratégias e comunicação, pois fornece uma maneira simplificada de visualização de um ambiente complexo e dinâmico (EL GIBARI; GÓMEZ; RUIZ, 2019). Para os produtores agrícolas, a importância do trabalho se revela pela possibilidade de verificação prática sobre quais pontos fracos, em termos de sustentabilidade, devem atuar, pensando e implementado estratégias, individuais ou coletivas, para avançar nestes quesitos. Para os agentes públicos, a pesquisa aponta direções nas quais as políticas públicas setoriais podem seguir. E para os consumidores, também se abre potencial fonte de informação sobre o nível de sustentabilidade dos estabelecimentos agrícolas, principalmente como requisito aos padrões de consumo consciente, com demanda crescente, e que levam em consideração questões sociais e ambientais do setor produtivo.

Além dessa seção introdutória, o artigo está dividido em outras cinco seções. Na seção dois é apresentada uma breve exposição teórica sobre sustentabilidade na agricultura. Na seção três demonstrase a abordagem metodológica, incluindo os indicadores simples empregados e os passos do método TOPSIS para 
construção dos indicadores compostos. Os resultados e as discussões são apresentados na seção quatro. A seção cinco traz as considerações finais e as referências encerram o estudo.

\section{SUSTENTABILIDADE NA AGRICULTURA}

As tecnologias sustentáveis são as que promovem sistemas socioeconômicos mais justos e conservação ambiental de maneira simultânea (SOUZA FILHO, 2012). No que tange a sustentabilidade na agricultura, Souza Filho (2012) apresenta alguns termos comumente empregados neste campo de pesquisa. No que se referem às práticas específicas ou sistemas, tem-se a agricultura orgânica, o plantio direto, o manejo integrado de pragas, a compostagem, a adubação verde, a rotação de culturas, entre outros. E em termos mais amplos, citamse a agricultura alternativa, a agricultura ecológica, a agricultura sustentável de baixo uso de insumos externos, entre outros.

As dificuldades de se exprimir uma definição categórica de agricultura sustentável são grandes, devido a sua imensa variação (LATRUFFE; DESJEUX, 2016; HAYATI, 2017). Apesar destas dificuldades, a sustentabilidade na agricultura deve abranger as dimensões econômica, social ambiental, no que tange a produção de bens e serviços, a contribuição e cuidado para com as comunidades rurais, e ao gerenciamento dos recursos naturais, respectivamente (KELLY et al., 2018).

Cavalcanti (2012, p. 46-47) afirma que a sustentabilidade para ser útil aos seres humanos deve estar suportada:

[...] na manutenção, reposição e crescimento dos ativos de capital, tanto físicos quanto humanos; na manutenção das condições físicas ambientais dos constituintes do bem-estar; no fortalecimento da resiliência dos sistemas terrestres, capacitando-os a ajustar-se a choques e crises; e em evitar transferir dívidas de qualquer caráter, ecológicas ou financeiras, para gerações futuras.

Ainda de acordo com Cavalcanti (2012), o desenvolvimento sustentável deve ser tratado como um processo socioeconômico, através do qual o bem-estar social deve ser maximizado ao mesmo tempo em que o uso dos recursos naturais seja feito de maneira eficiente para a minimização dos impactos ambientais.

Reifschneider e Lopes (2015) chamam a atenção para a importância da sustentabilidade, mais especificamente a sustentabilidade econômica, que é essencial para a permanência do pequeno produtor no campo. De acordo com os autores, a permanência do produtor rural no campo só é possível se este tiver a capacidade de auferir rendimentos em sua propriedade que lhe permitam atender às necessidades de sua família, quais sejam, a alimentação, a saúde, a educação e o lazer.

Ainda para Reifschneider e Lopes (2015), a produtividade é necessária para garantir a rentabilidade do produtor e, também, para o atendimento da demanda por alimentos, cada vez maior; a equidade seria importante para uma distribuição mais justa dos benefícios da agricultura; a resiliência para possibilitar a recuperação do sistema após estresses no processo produtivo e de comercialização; e a estabilidade para que ao longo do tempo as características dos sistemas sejam mantidas. Neste sentido, de acordo com os autores, a criticalidade da sustentabilidade, e que é aplicável a agricultura, em especial à horticultura, é a " [...] defesa e a preservação para uso das presentes e futuras gerações, bem como a recuperação do que foi degradado para que possa ser utilizado, defendido e preservado" (REIFSCHNEIDER; LOPES, 2015, p. 93).

\subsection{Mensuração da sustentabilidade por meio de indicadores}

Os indicadores de sustentabilidade, sejam utilizados de forma isolada ou condensados, são importantes instrumentos para a avaliação da sustentabilidade (COSTA, 2010). Parris e Kates (2003) definem os indicadores de sustentabilidade como medições quantitativas de variáveis que representam a sustentabilidade. McCool (2004) descreve os indicadores de sustentabilidade como métricas usadas para representar o desempenho de sistemas. Já Dantsis et al. (2010), expõem que os indicadores de sustentabilidade vêm sendo usados para entender e mensurar a performance da sustentabilidade a nível de propriedades rurais. Os autores adicionam ainda que os indicadores podem ser utilizados de forma individual ou agregada, de maneira que sejam combinados para formar um único valor. Xavier et al. (2018) ressaltam a capacidade que os indicadores agregadores têm de prover informação de forma simplificado, possibilitando inclusive comparações entre regiões. Areal et al. (2018) salientam, apesar disso, que diferentes pesos para os critérios de avaliação podem resultar em diferentes indicadores para cara propriedade rural, podendo-se acarretar errôneas apreciações. 
A escolha de quais indicadores utilizar para mensurar o nível de sustentabilidade agrícola está diretamente relacionada com o conceito de sustentabilidade adotado e, dessa forma, também é caracterizada pela não existência de consenso quanto a definição e em relação à escolha dos indicadores. Conforme Hayati, Ranjbar e Karami (2010), a sustentabilidade na agricultura é um conceito que, devido a sua alta complexidade, não apresenta consenso na literatura acerca da sua exata definição e dimensões. Da mesma forma, para sua mensuração também não há concordância e vários parâmetros têm sido sugeridos para tal tarefa.

Rasul e Thapa (2003) argumentam que a grande quantidade de indicadores desenvolvidos não tem considerado todas as dimensões sugeridas por WirénLehr (2001). Isto porque, de acordo com os autores, os indicadores adequados a um país não são necessariamente adequados a outros, devido as diferenças biofísicas e socioeconômicas existentes entre eles.

Hayati, Ranjbar e Karami (2010) em estudo que revisa aspectos das medidas utilizadas para mensurar a sustentabilidade agrícola, fazendo uma revisão de literatura em 41 trabalhos, no período de 1991 a 2007, sugerem e utilizam diferentes indicadores para a sustentabilidade agrícola. Os autores verificaram que, de maneira geral, três componentes recebem ênfase: social, econômica e ecológica. Ainda que os parâmetros utilizados para cada componente possam sofrer variações, os autores sugerem que suas escolhas devem ser feitas com base nas especificidades locacionais.

Bachev (2017), por exemplo, em estudo que buscou levantar a sustentabilidade na agricultura na Bulgária, considerou como dimensões, além da econômica, social e ambiental, também uma dimensão de governança sustentável. Os resultados do trabalho do referido autor demonstraram haver uma superioridade nas dimensões sociais e ambientais. Sulewski, Gajewska e Sroka (2018) utilizaram como dimensões da sustentabilidade na agricultura os critérios econômico, social e ambiental, em trabalho desenvolvido na Polônia, no qual, além de mensurar a sustentabilidade dos produtores rurais, também analisaram a interdependência entre as dimensões, concluindo haver dependência positiva entre elas. $\mathrm{Na}$ Turquia, o trabalho de Haq e Boz (2020), que também se utiliza de indicadores compostos para mensurar as dimensões econômica, social e ambiental da sustentabilidade na agricultura, concluíram que a dimensão social é a de melhor avaliação.

No presente trabalho, as dimensões da sustentabilidade consideradas para a escolha dos indicadores foram as defendidas, entre diversos autores já citados, por Wirén-Lehr (2001), para que as dimensões básicas para avaliar a sustentabilidade agrícola em termos normativas, devem levar em consideração aspectos econômicos, sociais e ecológicos ou ambientais.

A abordagem metodológica para escolha dos indicadores neste trabalho segue o que sugere Costa (2010), pois se adequam a realidade do problema a ser avaliado. Também conforme Müller (1996) e LópezRidaura, Masera e Astier (2002), os indicadores podem ser escolhidos de acordo com o problema de pesquisa, com a região geográfica e questões sócioeconômica, também de forma a se moldar a problemática de pesquisa. Isto é necessário porque, de acordo com Costa (2010), não existem indicadores universais de sustentabilidade. A seguir apresenta-se a explanação sobre os indicadores utilizados para mensurar a sustentabilidade no presente trabalho.

\section{ABORDAGEM METODOLÓGICA}

Os indicadores simples de sustentabilidade utilizados nesta pesquisa foram selecionados com o intuito de formar um conjunto de indicadores representativos da sustentabilidade na agricultura. Os critérios para a seleção de indicadores foram: a) disponibilidade de informações sobre o desempenho dos produtores agrícolas. Neste critério faz-se necessário observar que a aplicação dos questionários aos produtores levou em consideração o tempo de aplicação de cada questionário, bem como o acesso à informações que os produtores não estavam dispostos a oferecer; b) restrições orçamentárias da avaliação, que estão no conjunto de critérios sugeridos pela FAO (2013) e Binder et al. (2010), e que no caso da presente pesquisa, havia necessidade de deslocamento e também de tempo dos pesquisadores; e c) orientação para objetivos específicos da análise (BINDER et al., 2010). Neste critério se encontra o pilar da escolha dos indicadores simples, pois todos estes indicadores já vêm sendo utilizado na literatura que trata da sustentabilidade na agricultura. Hayati, Ranjbar e Karami, por exemplo, fazem uma revisão da literatura a respeito do tema, que subsidia e justifica a escolha dos referidos indicadores.

O Quadro 1 mostra as dimensões e indicadores simples utilizados para medir a sustentabilidade na agricultura no presente trabalho e apresenta também outras informações complementares a respeito de cada indicador. Na terceira coluna é possível observar uma descrição resumida de cada indicador, ou seja, 


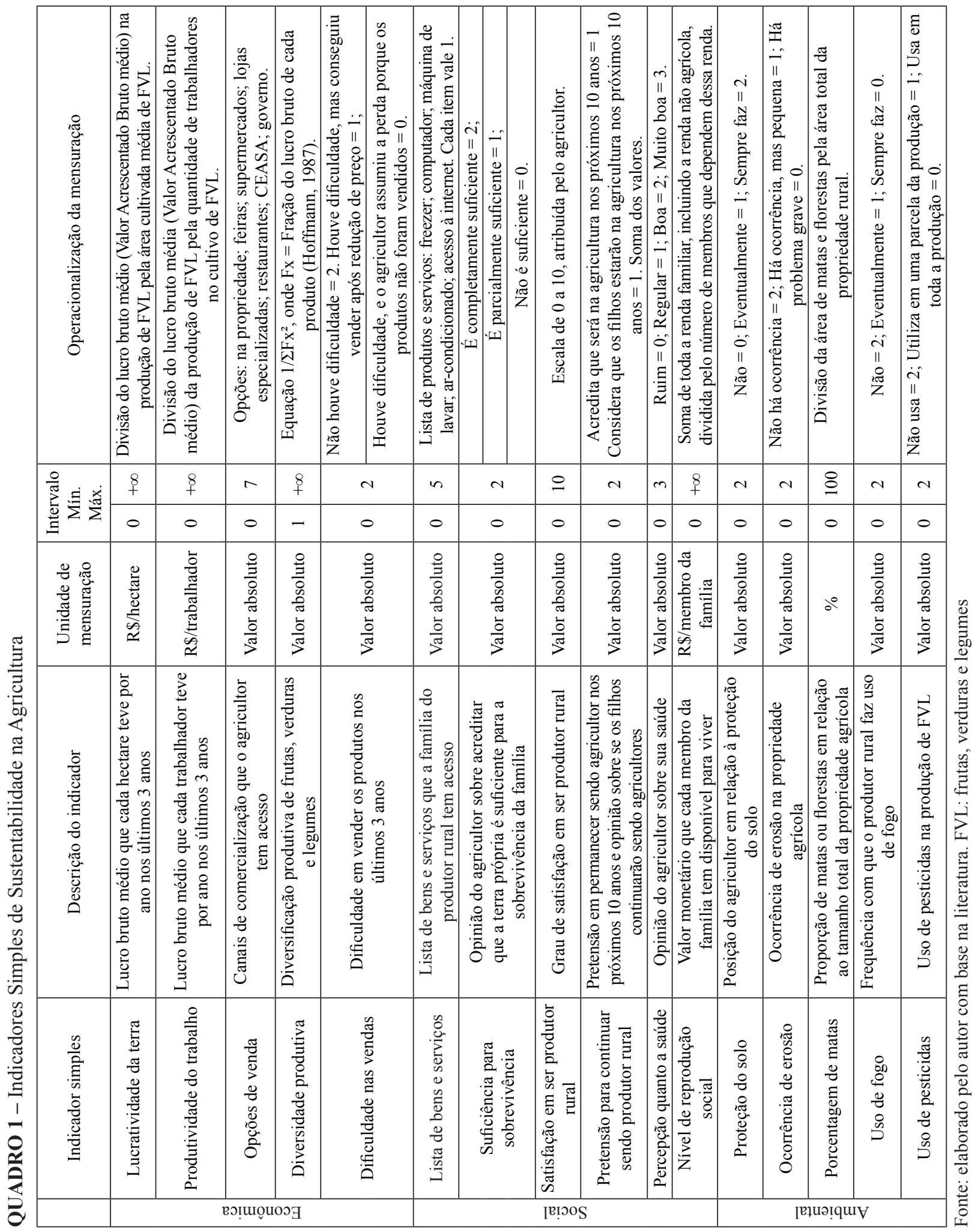

Organizações Rurais \& Agroindustriais, Lavras, 22:e1515, 2020 
seus respectivos significados. A quarta coluna traz a unidade de mensuração dos indicadores, que podem ser representados somente por um valor absoluto ou por um valor relativo. O intervalo teórico sobre os possíveis valores dos indicadores mensurados pode ser observado na quinta coluna. Nesta coluna, observase, por exemplo, que o intervalo do indicador simples Porcentagem de matas, varia de 0 à 100 , significando que a propriedade rural, teoricamente, pode não possuir nenhuma mata ou ser completamente coberta por matas. $\mathrm{Na}$ última coluna apresenta-se a forma, bem como as alternativas de resposta com seus respectivos valores, para a operacionalização da mensuração do valor de cada indicador para cada produtor rural.

Os indicadores simples foram agregados em indicadores compostos, em cada dimensão da sustentabilidade e, também, em um indicador composto total, que pretende apontar o nível de sustentabilidade como um todo dos produtores rurais.

Os indicadores compostos são ferramentas importantes, tanto no que se refere à elementos de análise, como também instrumentos facilitadores de comunicação de informações. Esses têm o potencial de apresentar informações simplificadas de contextos complexos, como a sustentabilidade na agricultura. De acordo com El Gibari, Gómez e Ruiz (2018), as técnicas de Multi-criteria decision making (MCDM) são altamente adequadas em estruturas multidimensionais para agregar indicadores simples em indicadores compostos, possibilitando a combinação de critérios de diferente natureza, e assim podendo ser implementados por meio de um determinado número de etapas.

O método MCDM utilizado neste trabalho é baseado em funções de distância, que segundo DíazBalteiro (2017), têm como ideia implícita a substituição de uma função de maximização, por uma função de minimização da distância entre uma observação e um ou alguns pontos com boas propriedades preferenciais. Especificamente neste trabalho, utilizou-se o método TOPSIS introduzido por Hwang e Yoon (1981), que consiste em avaliar a sustentabilidade de uma observação medindo o quão longe ela está de dois pontos de referência, o ponto ideal e o ponto anti-ideal, ou solução ideal negativa. Quanto mais próximo da solução ideal, e mais longe da solução anti-ideal, melhor o nível de sustentabilidade. De acordo com Kahraman (2008), a solução ideal é calculada levando-se em consideração os melhores resultados de todos os critérios, ou seja, dos indicadores simples, de cada observação estudada.
A solução ideal negativa é computada de forma similar, tomando-se os piores valores.

A utilização convencional do método TOPSIS emprega, no entanto, para a ponderação dos indicadores simples, a opinião e atribuição de pesos feitas por especialistas. Nesta pesquisa, a ponderação foi feita através do método de entropia, assim como já sugerido e realizado em outros trabalhos, como Chen, Wang e Den (2015), Hafezalkotob e Hafezalkotob (2016) e Wang, Dai e Wang (2017).

O método de entropia atribui pesos a cada indicador, de forma automatizada, ou seja, pondera cada indicador, com base justamente na entropia fornecida pelos valores desses indicadores (NGODUY; MAHER, 2012). Como também afirma Gray (2011), o método de entropia pode ser consistente para o presente trabalho, como um parâmetro estatístico que é capaz de mensurar a quantidade de informação que é produzida por cada indicador.

Os passos do método TOPSIS para o cálculo do índice composto de sustentabilidade são apresentados na Figura 1. Em seguida, cada um dos passos é explicado, resumidamente. O método utilizado é suavemente adaptado de Chakraborty e Yeh (2009), Çelen (2014) e Chen (2015).

Passo 1. Identificação da matriz de indicadores simples A matriz $X=\left(x_{\mathrm{ij}}\right)_{m \times n}$ mostra todos os valores das observações $i(1 \leq i \leq m)$ em relação ao critério $j(1 \leq j \leq n)$. Sendo assim, a matriz de indicadores simples terá o seguinte formato:

$X=\left[\begin{array}{cccc}x_{11} & x_{12} & \ldots & x_{1 n} \\ x_{21} & x_{22} & \ldots & x_{2 n} \\ \vdots & \vdots & \ldots & \vdots \\ x_{m 1} & x_{m 2} & \ldots & x_{m n}\end{array}\right]$

Passo 2. Normalização da matriz de indicadores simples Como os indicadores têm diferentes dimensões, isto é, escalas ou unidades, neste passo é realizada a normalização dos dados, para que esses possam ser combinados. O objetivo da normalização é possibilitar que os indicadores possuam a mesma magnitude. $\mathrm{O}$ valor normalizado é calculado como segue:

$Y_{i j}=\frac{X_{i j}}{\sqrt{\sum_{k=1}^{m}\left(X_{k j}\right)^{2}}}, i=1,2, \ldots, m ; j=1,2, \ldots, n$. 


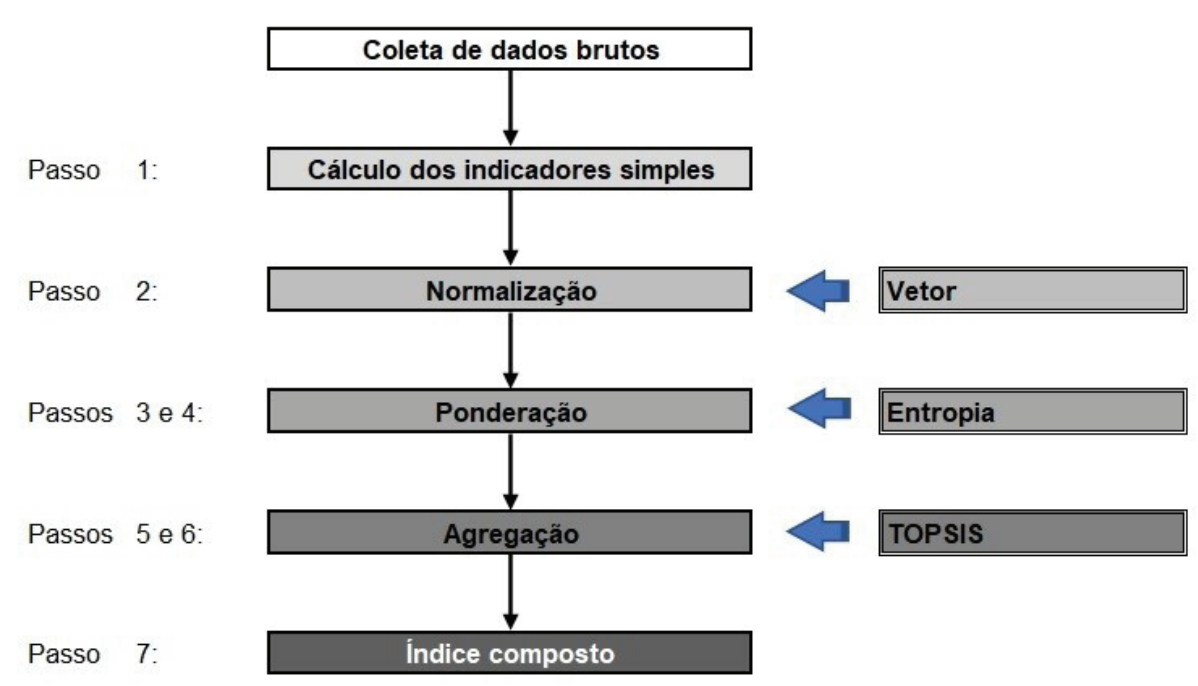

FIGURA 1 - Fluxograma resumo do método para cálculo do índice composto de sustentabilidade Fonte: Elaborado pelos autores.

Passo 3. Atribuição de pesos aos indicadores Valor da entropia ${ }^{1}$ dos indicadores

$E_{j}=-\frac{1}{\ln m} \sum_{i=1}^{m} p_{i j} \ln p_{i j}$

Onde

$p_{i j}=\frac{Y_{i j}}{\sum_{k=1}^{m} Y_{k j}}, i=1,2, \ldots, m ; j=1,2, \ldots, n$

A matriz ponderada dos indicadores simples é obtida como:

$W=\left[\begin{array}{cccc}\omega_{1} & 0 & \ldots & 0 \\ 0 & \omega_{2} & \ldots & 0 \\ \vdots & \vdots & \ldots & \vdots \\ 0 & 0 & \ldots & \omega_{n}\end{array}\right]$

Passo 4. Calcular a matriz de indicadores simples normalizada ponderada

Multiplica-se a matriz de indicadores simples normalizada pela matriz ponderada dos indicadores. A matriz normalizada e ponderada dos indicadores simples será dada por:

${ }^{1}$ Para uma visão mais detalhada sobre o significado e cálculo da entropia, consultar de Boer et al. (2005)).

$$
Z_{i j}=Y_{i j} W_{i j}, i=1,2, \ldots, m ; j=1,2, \ldots, n \text {. }
$$

Passo 5. Determinar as soluções ideais Solução Ideal Positiva (SIP)

$$
Z^{+}=\left(z_{1}^{+}, z_{2}^{+}, \ldots, z_{n}^{+}\right)
$$

Solução Ideal Negativa (SIN)

$Z^{-}=\left(z_{1}^{-}, z_{2}^{-}, \ldots, z_{n}^{-}\right)$

Onde

$z_{j}^{+}=\max _{1 \leq i \leq m}\left\{z_{i j}\right\}, z_{j}^{-}=\min _{1 \leq i \leq m}\left\{z_{i j}\right\}, j=1,2, \ldots, n$.

Passo 6. Calcular as distâncias Euclidianas de cada alternativa SIP e SIN

Essa etapa se refere a medida de separação, para cada observação $z_{i,}$, em relação as soluções ideal e anti-ideal. A separação para SIP é dada por:

$D_{i}^{+}=\sqrt{\sum_{j}^{n}\left(z_{i j}-z_{j}^{+}\right)^{2}}, i=1,2, \ldots, m ; j=1,2, \ldots, n$.

A separação para SIN é dada por:

$$
D_{i}^{-}=\sqrt{\sum_{j}^{n}\left(z_{i j}-z_{j}^{-}\right)^{2}}, i=1,2, \ldots, m ; j=1,2, \ldots, n .
$$


Passo 7. Calcular o coeficiente de proximidade de cada observação

O coeficiente de proximidade será o índice composto de cada observação. Esta se refere a aproximação de cada observação em relação a solução ideal positiva, e é dada pela fórmula:

$C_{i}=\frac{D_{i}^{-}}{D_{i}^{+}+D_{i}^{-}}, i=1,2, \ldots, m$.

Quanto mais próximo de 1, mais próximo da situação ideal está o produtor rural. Quanto mais próximo de 0 , mais longe da situação ideal (e mais próximo da situação não ideal) está o produtor ideal.

\subsection{Amostra e Coleta dos Dados}

A população foco deste trabalho é formada por produtores agrícolas de frutas e verduras da microrregião de Toledo, estado do Paraná (Figura 2). O quantitativo populacional foi assumido como sendo de um total de 497 produtores, pois é o número disponibilizado pelo Censo Agropecuário de 2006. Nas entrevistas com os produtores da amostra foi feito um levantamento da quantidade de produtores agrícolas de frutas e verduras em cada município, e o número levantado foi de 460 produtores, que é um número aproximado do Censo Agropecuário de 2006.

A amostragem nesta pesquisa foi a não probabilística, pois o acesso à informação populacional e amostral não estavam disponíveis. Foram utilizados os dados que se conseguiram obter ao longo da pesquisa. A forma da amostra pode ser definida como amostragem por acessibilidade em cada município em que houve coleta de dados (Municípios: Assis Chateaubriand, Diamante do Oeste, Entre Rios do Oeste, Formosa do Oeste, Guaíra, Iracema do Oeste, Jesuítas, Marechal Cândido Rondon, Maripá, Mercedes, Nova Santa Rosa, Ouro Verde do Oeste, Pato Bragado, Quatro Pontes, Santa Helena, São José das Palmeiras, São Pedro do Iguaçu, Terra Roxa, Palotina e Toledo), que corresponde ao caso em que se seleciona como amostra elementos da população aos quais se tem acesso, de forma a tornar a pesquisa possível.

A coleta de dados foi feita através de aplicação de questionários estruturados aos produtores agrícolas no período entre o dia 01 de dezembro de 2016 e o dia 20 de janeiro de 2017. Quatro pessoas fizeram parte da equipe

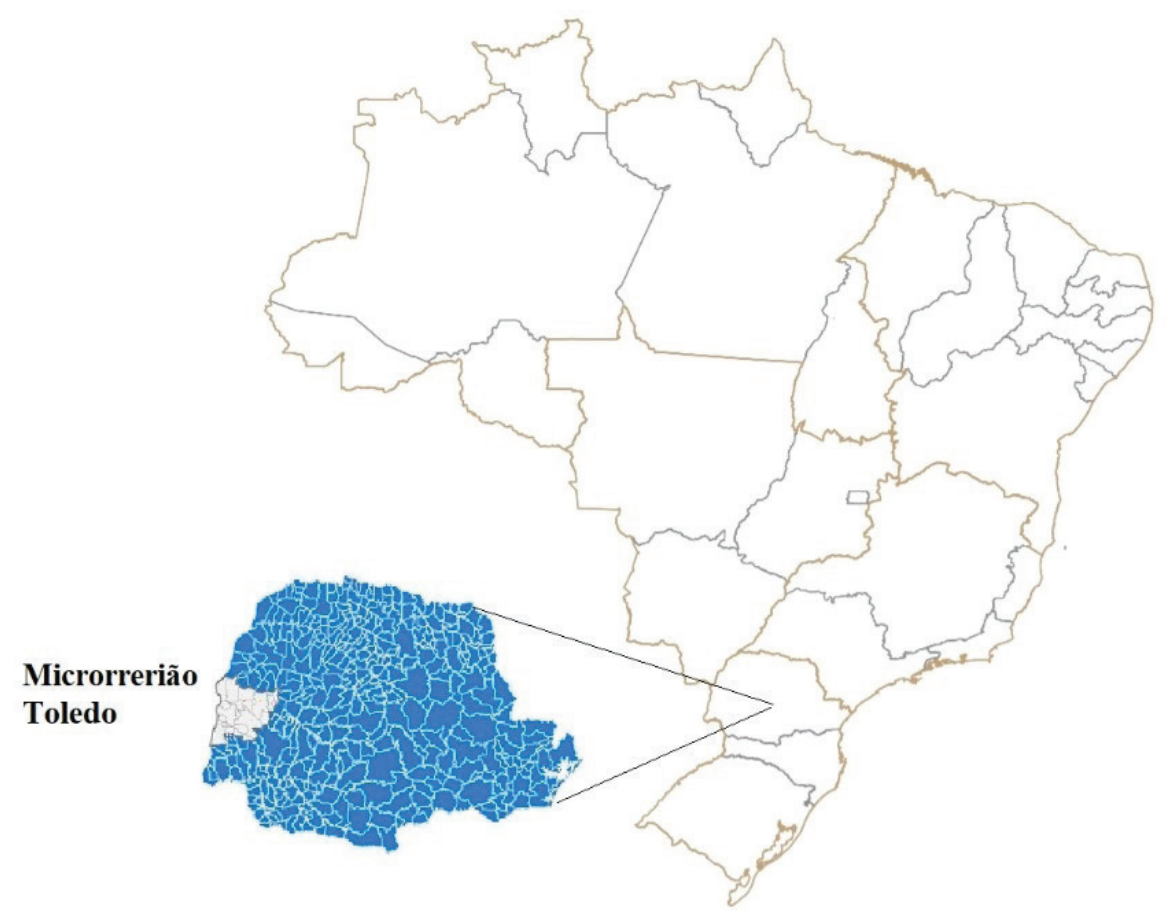

FIGURA 2 - Localização da microrregião de Toledo, Estado do Paraná, Brasil Fonte: IPARDES, 2019.

Organizações Rurais \& Agroindustriais, Lavras, 22:e1515, 2020 
de coleta de dados, incluindo um dos autores deste estudo, que realizou o devido treinamento com os outros três entrevistadores e, também, supervisionou todo o processo de coleta de dados. A amostra populacional deste trabalho é composta de 99 produtores rurais, o que corresponde a aproximadamente $20 \%$ do total de produtores da microrregião.

\section{RESULTADOS E DISCUSSÕES}

Nesta seção apresentam-se os resultados e as discussões em relação aos indicadores de sustentabilidade dos produtores de frutas, verduras e legumes da microrregião de Toledo, PR.

A Tabela 1 apresenta os valores das médias aritméticas dos indicadores simples e compostos. A terceira coluna se refere aos valores das médias dos valores primários dos 16 indicadores simples de sustentabilidade para a microrregião. A quarta coluna indica esses valores após serem normalizados . Nas colunas cinco e seis são apresentados os valores médios dos índices compostos por dimensão, ou seja, a composição considerou somente os indicadores simples de cada dimensão. As duas últimas colunas apresentam o valor médio, para a microrregião, do indicador de sustentabilidade composto geral, ou seja, considerando todos os 16 indicadores simples.

Os resultados evidenciados na Tabela 1 permitem uma visão abrangente do nível de sustentabilidade dos produtores agrícolas que fizeram parte do estudo, que é justamente um dos objetivos da utilização de indicadores compostos, isto é, condensar em apenas um indicador, neste caso, a informação sobre 16 indicadores simples de sustentabilidade.

Levando-se em consideração o critério metodológico do método TOPSIS adotado neste trabalho, de que quanto mais próximo de 1, mais próximo da situação ideal; e de que quanto mais próximo de 0 , mais longe da situação ideal está o produtor, verifica-se por meio da Tabela 1 que na microrregião estudada, considerando o valor médio dos produtores, estes não estão próximos de uma situação ideal de sustentabilidade. $\mathrm{O}$ indicador composto de sustentabilidade geral revelou-se estar mais próximo de 0 do que de 1 , com um valor de 0,325 . Tal resultado revela que o nível de sustentabilidade agrícola é efetivamente baixo, e abre espaço para algumas observações diagnósticas de tal cenário.

TABELA 1 - Resultado dos valores médios dos indicadores simples e compostos para a Microrregião de Toledo, PR

\begin{tabular}{|c|c|c|c|c|c|c|c|c|}
\hline \multirow[b]{2}{*}{ Código } & \multirow[b]{2}{*}{ Indicador simples } & \multicolumn{2}{|c|}{ Média dos dados } & \multirow[t]{2}{*}{ Pesos } & \multirow{2}{*}{\multicolumn{2}{|c|}{$\begin{array}{c}\text { Índices } \\
\text { compostos } \\
\text { das dimensões }\end{array}$}} & \multirow{2}{*}{\multicolumn{2}{|c|}{$\begin{array}{c}\text { Índice } \\
\text { composto de } \\
\text { sustentabilidade }\end{array}$}} \\
\hline & & Primários & Normalizados & & & & & \\
\hline ISE1 & Produtividade da terra & 28.535 & 0,323 & 0,197 & \multirow{5}{*}{ 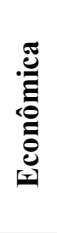 } & \multirow{5}{*}{0,324} & \multirow{16}{*}{ 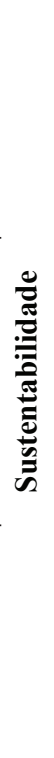 } & \multirow{16}{*}{0,325} \\
\hline ISE2 & Produtividade do trabalho & 16.668 & 0,209 & 0,306 & & & & \\
\hline ISE3 & Opções de venda & 2,72 & 0,429 & 0,112 & & & & \\
\hline ISE4 & Diversidade produtiva & 2,53 & 0,339 & 0,342 & & & & \\
\hline ISE5 & Dificuldade nas vendas & 1,17 & 0,545 & 0,044 & & & & \\
\hline ISS1 & Lista de bens e serviços & 3,48 & 0,303 & 0,312 & \multirow{6}{*}{$\begin{array}{l}\bar{\pi} \\
\stackrel{\pi}{0} \\
\mathscr{0}\end{array}$} & \multirow{6}{*}{0,305} & & \\
\hline ISS2 & Suficiência para sobrevivência & 1,49 & 0,268 & 0,097 & & & & \\
\hline ISS3 & Satisfação em ser produtor rural & 8,81 & 0,149 & 0,227 & & & & \\
\hline ISS4 & Pretensão para continuar sendo produtor rural & 1,18 & 0,409 & 0,017 & & & & \\
\hline ISS5 & Percepção quanto a saúde & 2,82 & 0,394 & 0,305 & & & & \\
\hline ISS6 & Nível de reprodução social & 18.044 & 0,813 & 0,043 & & & & \\
\hline ISA1 & Proteção do solo & 1,63 & 0,187 & 0,444 & \multirow{5}{*}{ 䏤 } & \multirow{5}{*}{0,326} & & \\
\hline ISA2 & Ocorrência de erosão & 1,69 & 0,157 & 0,161 & & & & \\
\hline ISA3 & Porcentagem de matas & $12 \%$ & 0,750 & 0,075 & & & & \\
\hline ISA4 & Uso de fogo & 1,84 & 0,152 & 0,166 & & & & \\
\hline ISA5 & Uso de pesticidas & 1,18 & 0,409 & 0,154 & & & & \\
\hline
\end{tabular}

Fonte: Elaborado pelos autores. 
Devido à concentração na produção de commodities, a área de terra dedicada a produção de frutas, verduras e legumes na microrregião é direcionada de forma majoritária para atendimento da demanda local. A produção se enquadra de forma predominante, considerando a tipologia dos circuitos de produção e comercialização, nos circuitos curtos que, como sugere Mundler (2008), são caracterizados pela venda dos produtos de forma direta para os consumidores, ou a venda indireta com a participação de apenas um intermediário entre produtor e consumidor. De maneira mais específica, os circuitos de comercialização utilizados pelos produtores são a venda direta na propriedade, venda direta em feiras, venda indireta através de supermercados, lojas especializadas, restaurantes e órgãos governamentais, como escolas, creches e hospitais.

Uma identificação quanto a potenciais inibidores de maiores índices de sustentabilidade na microrregião se refere às imperfeições do processo de comercialização, como por exemplo, a dependência apenas do mercado local, e a concorrência de grandes redes de supermercados, que pode acarretar consequente baixa remuneração do esforço.

Neste aspecto, demanda-se, por parte dos produtores, uma melhor estratégia de comercialização, principalmente com relação à propaganda para uma maior inserção nos mercados locais e para os maiores centros de consumo. Em termos locais, seria necessário que esta estratégia ressaltasse a qualidade dos alimentos, e o incentivo da população local ao consumo de produtos locais.

As estratégias e sugestões para se alcançar mais altos níveis de sustentabilidade na agricultura são bastante discutidas na literatura, sendo este um assunto ainda fortemente debatido. Dentre estas estratégias, principalmente no setor de frutas, verduras e legumes está o comércio fair trade. Este é um mercado cujo setor produtivo na microrregião analisada não tem atuação e está diretamente ligado às dimensões sociais e ambientais da sustentabilidade. De acordo com Mohan (2010) e FerroSoto; Mili (2013), a essência da ideia defendida pelo fair trade é fazer do comércio mundial uma atividade mais justa, principalmente para os pequenos produtores que estão no início da cadeia de produção e comercialização. $\mathrm{O}$ instrumento utilizado para isso seria a adoção de um preço adequado que os pequenos produtores deveriam receber, facilitando, desta forma, o acesso por parte destes ao mercado internacional.
Nesta perspectiva, o fair trade defende também uma maior preocupação com as questões sociais e ambientais, no intuito de diminuir desequilíbrios causados pela disputa exacerbada no comércio mundial convencional, principalmente de commodities agrícolas, que em não raras vezes, funciona com um preço inferior ao necessário para a subsistência dos pequenos produtores. Com relação a possibilidade de expansão a mercados alternativos, de acordo com Schneider (2012), as frutas secas, por exemplo, são produtos com demanda crescente no mercado europeu, devido à preferência por produtos que possuem apelo socioambiental. Este segmento de produtos com certificação socioambiental, do qual o fair trade é componente, e apoia práticas produtivas e comerciais que prezem pela conservação do ambiente natural, estando os consumidores dispostos a pagar por produtos de qualidade, de maneira a compensar os produtores por adotarem práticas conservacionistas (OLIVEIRA; ARAÚJO; SANTOS, 2008).

Também Melo (2015) pontua que a categoria de frutas frescas exportadas pelo Brasil através do fair trade são laranjas, limões, limas, tangerinas, abacate, manga, abacaxi, melão, maçã, uva, pera e ameixa. A maioria destas frutas fazem parte do rol de produtos cultivados na microrregião de Toledo-PR e, assim, são potenciais candidatas para que os produtores, cooperativas e associações presentes na microrregião levem em consideração a atuação neste mercado.

Dos governos locais, campanhas para o consumo de produtos produzidos localmente, com preferência para produtos produzidos de forma sustentável, enfatizando a superioridade da qualidade destes alimentos, também poderiam ter efeitos benéficos em termos de sustentabilidade da agricultura regional.

Adicionalmente, percebe-se que os agricultores carecem de melhor uso das instituições públicas e privadas de ensino técnico e superior, pesquisa e desenvolvimento, e extensão rural presentes na região. Um maior e melhor relacionamento com estas instituições traria ganhos com relação a aquisição de informações técnicas, habilidades no uso de novas técnicas agrícolas e métodos de gerenciamento mais sofisticados, resultando em modernização e melhorias dos sistemas produtivos. Um dado que reforça esta constatação é que, $45 \%$ dos agricultores da amostra não tem nenhuma ou apenas esporadicamente acesso à assistência técnica.

Ressalta-se, no entanto, que a modernização tecnológica na agricultura, com frequência exige certa disponibilidade de capitalização. Assim, reforça-se a

Organizações Rurais \& Agroindustriais, Lavras, 22:e1515, 2020 
necessidade de maior geração de renda, que também traria aos produtores mais disposição para investir recursos financeiros e de tempo nas questões ambientais, alcançariam melhores condições sociais. Consequentemente, o nível geral de sustentabilidade poderia ser acrescido.

O método TOPSIS foi utilizado também para computar o índice composto de sustentabilidade para cada dimensão. Isto possibilita, além da verificação do nível de sustentabilidade dos produtores em cada dimensão separadamente, ainda a realização de comparações, já que as escalas e a unidade de medida do indicador são as mesmas.

Para os indicadores compostos das dimensões, os resultados demonstraram-se também distantes da situação ideal. $\mathrm{O}$ indicador composto de sustentabilidade econômica apurado foi de 0,324 . O de sustentabilidade social foi de 0,305 , sendo esse, inclusive, o índice inferior entre as três dimensões consideradas. No indicador composto de sustentabilidade ambiental, identificou-se o valor médio de 0,326 , sendo este o resultado mais positivo dentre as três dimensões. Haq e Boz (2017), apesar de utilizarem diferente metodologia para agregação dos indicadores, também mensuram o nível de sustentabilidade na agricultura por meio de indicadores compostos, com resultado variando no intervalo entre 0 e 1 . Diferentemente da presente pesquisa, Haq e Boz (2017) encontraram resultados desiguais entre a dimensões na Turquia, sendo na dimensão econômica o pior resultado $(0,23)$, seguida da ambiental $(0,43)$ e como melhor resultado, a dimensão social $(0,51)$. O indicador composto geral apresentou, para o mesmo trabalho, valor de 0,39 .

Apesar de apresentarem resultados relativamente aproximados, uma observação mais criteriosa sobre as três dimensões da sustentabilidade permite a verificação de que as dimensões ambiental e econômica são, nesta ordem, as que têm o melhor nível de sustentabilidade no presente trabalho. A dimensão social é a que apresenta pior desempenho. Este é um resultado que difere também parcialmente do resultado de Bachev (2017), que encontrou superiores níveis de sustentabilidade para as dimensões ambiental e social. Ressalta-se que, apesar de utilizar indicadores agregados, Bachev (2017) utilizou metodologia diversa, bem como, diferentes indicadores de sustentabilidade.

Com o intuito de melhor explorar os resultados dos indicadores de sustentabilidade já anunciados, em seguida, na Figura 3, demonstra-se de uma maneira diferente os referidos valores, através de boxplot. Assim, apresentam-se os indicadores simples, os indicadores compostos por dimensão da sustentabilidade e o indicador de sustentabilidade geral. Todos são valores médios para a microrregião de análise.

Na Figura 3 é possível visualizar também, além das médias dos indicadores simples e compostos de sustentabilidade, os valores mínimo e máximo, a mediana, o primeiro e terceiro quartil, além de possíveis outliers, ou seja, valores atípicos.

Ao se observar o boxplot, por exemplo, dos indicadores compostos das três dimensões da sustentabilidade estudados, verifica-se que na dimensão social a caixa é mais "achatada", o que é característico de um conjunto de dados com menor variabilidade e menor desvio padrão, se comparado com a dimensão ambiental. A caixa mais "alongada" nessa última dimensão, sugere uma maior variabilidade e desvio padrão nos dados.

Nas três dimensões, constata-se que o boxplot está posicionado na parte inferior do gráfico, indicando que tanto a média quanto a mediana dos valores estão mais próximos de 0 do que de 1 , ou seja, longe da situação ideal de sustentabilidade. A mesma afirmação pode ser feita em relação ao índice composto de sustentabilidade geral.

Com referência aos indicadores simples, destaca-se o posicionamento na parte superior do gráfico, indicando valores altos da média e da mediana, dos índices de nível de reprodução social e porcentagem de matas, apesar deste último apresentar maior variabilidade e desvio padrão.

Esta representação gráfica é uma adaptação do que foi proposto por Scandar Neto (2006) e é capaz de propiciar uma visão panorâmica sobre a situação da sustentabilidade dos produtores rurais de frutas, verduras e legumes na microrregião de Toledo, PR.

A análise pode ser iniciada pelo índice composto de sustentabilidade geral dos produtores, com um nível de informação extremamente agregada, sendo praticável a identificação de quais dimensões da sustentabilidade tem melhor e pior desempenho. Além disso, a representação gráfica possibilita também a verificação da realidade local, de uma forma mais desagregada dos dados, através da visualização dos desempenhos dos indicadores simples de sustentabilidade, sendo possível conjecturar quais estão influenciando o comportamento dos indicadores compostos.

Conforme argumentado por Scandar Neto (2006), uma das vantagens de se apresentar os indicadores nesse formato é que se quebra a dicotomia "indicador sintético x sistema de indicadores", no sentido de que a síntese, no caso o indicador composto, é uma ferramenta descritiva poderosa, mas que, porém, não pode ignorar o sistema ou o todo. 

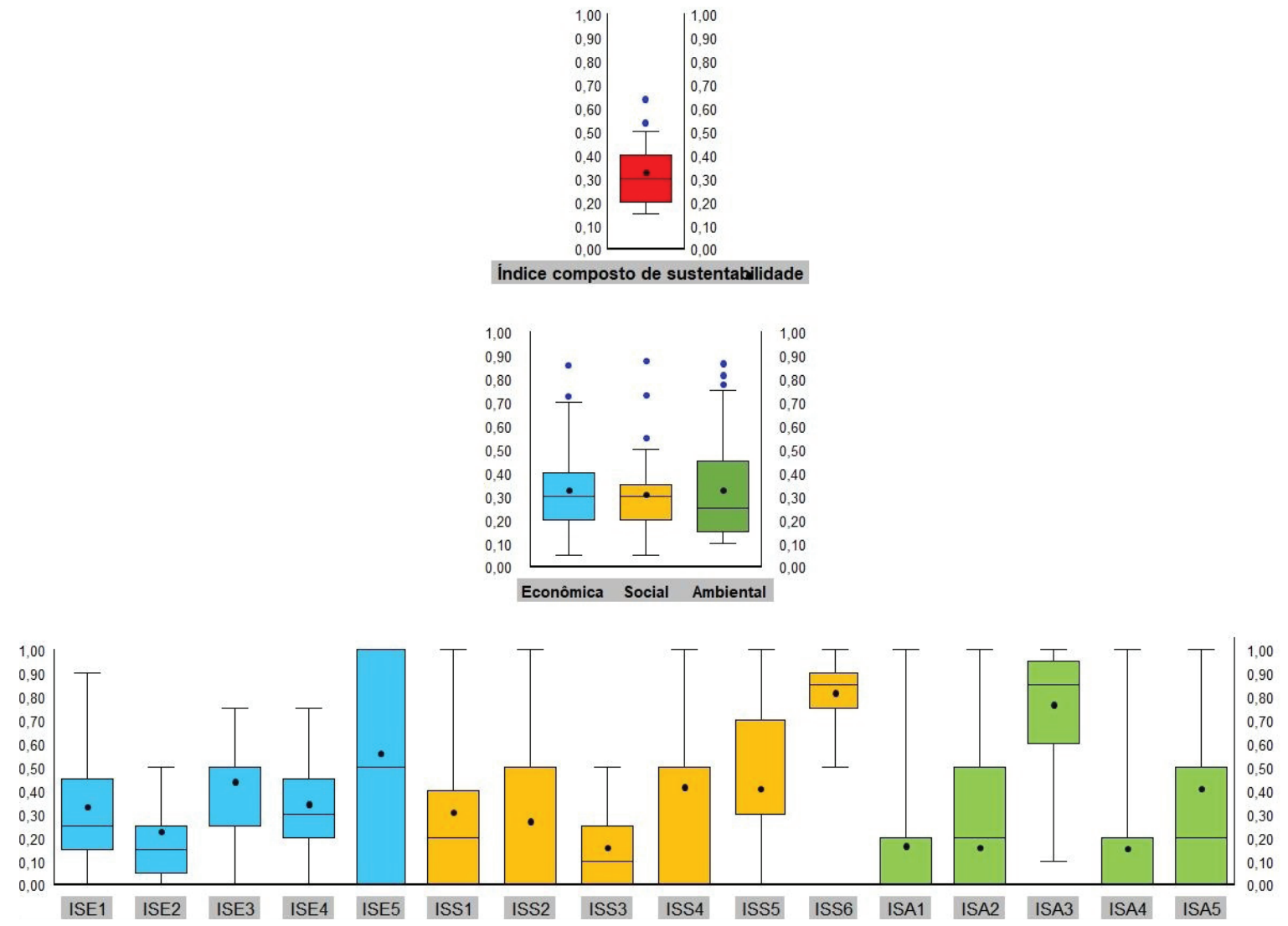

FIGURA 3 - Boxplot dos valores médios dos indicadores simples e compostos para a Microrregião de Toledo, PR Fonte: Elaborado pelos autores

Um outro gráfico, complementar ao boxplot, é apresentado na Figura 4, a fim de proporcionar um melhor entendimento sobre a amostra estudada. Trata-se de um histograma de frequência dos índices compostos de sustentabilidade de cada dimensão e o índice composto total. No eixo horizontal de cada gráfico estão representados os intervalos de valores dos índices compostos e nos eixos verticais a frequência, ou seja, a quantidade de produtores que apresentaram indicadores em cada intervalo.

Na dimensão econômica, o intervalo é o que expõe maior frequência, com 28 produtores dos 99 da amostra manifestando índices neste intervalo. No intervalo de a quantidade de produtores computados foi de 26. Nestes dois intervalos, se encontram $54,5 \%$ da amostra do estudo.

$\mathrm{Na}$ dimensão social, também o intervalo é o que tem maior frequência, contendo 37 produtores. No intervalo a quantidade é de 35 produtores. Juntos, estes dois intervalos contêm $72,7 \%$ da amostra.
Já na dimensão ambiental, o intervalo que expõe a maior frequência, 31 produtores, está entre os valores . No intervalo de foram computados 24 produtores. Nestes dois intervalos, com as maiores frequências, a soma dos produtores corresponde à $55,5 \%$ da amostra de produtores.

Uma observação importante, que diz respeito tanto a dimensão social, como também ambiental, é que boa parte dos agricultores demonstraram, durante a realização da pesquisa de campo, ter a perspectiva de estar na agricultura apenas por algum tempo e, demonstram intenção de atuar em outros setores. Dessa forma, pensam que se engajar em estratégias e ações que trariam retornos a curto prazo pois num futuro próximo não vão estar mais na agricultura. Esta é uma atitude não condizente com atividades sustentáveis, pois estas, em geral, oferecem expectativas de retornos no longo prazo.

Especificamente em relação às questões ambientais, Hazell et al. (2007) argumentam que as externalidades provenientes da atividade agrícola é um assunto de difícil 
debate. Segundo os autores, esta é uma discussão quando os custos da degradação dos recursos naturais não são facilmente imputados aos agentes que realizam esta degradação. Como exemplo, os autores citam a derrubada de árvores e matas nos leitos dos rios, que podem ser benéficas no curto prazo para os produtores agrícolas, mas que podem trazer problemas de assoreamento ou inundações para as comunidades próximas. Hazel et al. (2007) citam como problemas relacionados à conservação dos recursos naturais as externalidades intergeracionais, na medida em que o uso de recurso pelos agricultores no presente possa exauri-los, de forma a prejudicar o seu uso futuro.

$\mathrm{Na}$ presente pesquisa, pode-se citar como fatos semelhantes aos citados por Hazel et al. (2007), além da derrubada de matas e florestas em locais prejudiciais aos rios, a realização de queimadas e o uso de pesticidas, com consequências para as comunidades próximas aos produtores que porventura realizam tais práticas. Com respeito as externalidades intergeracionais, tem-se as práticas de proteção ao solo e os cuidados com a ocorrência de erosão.
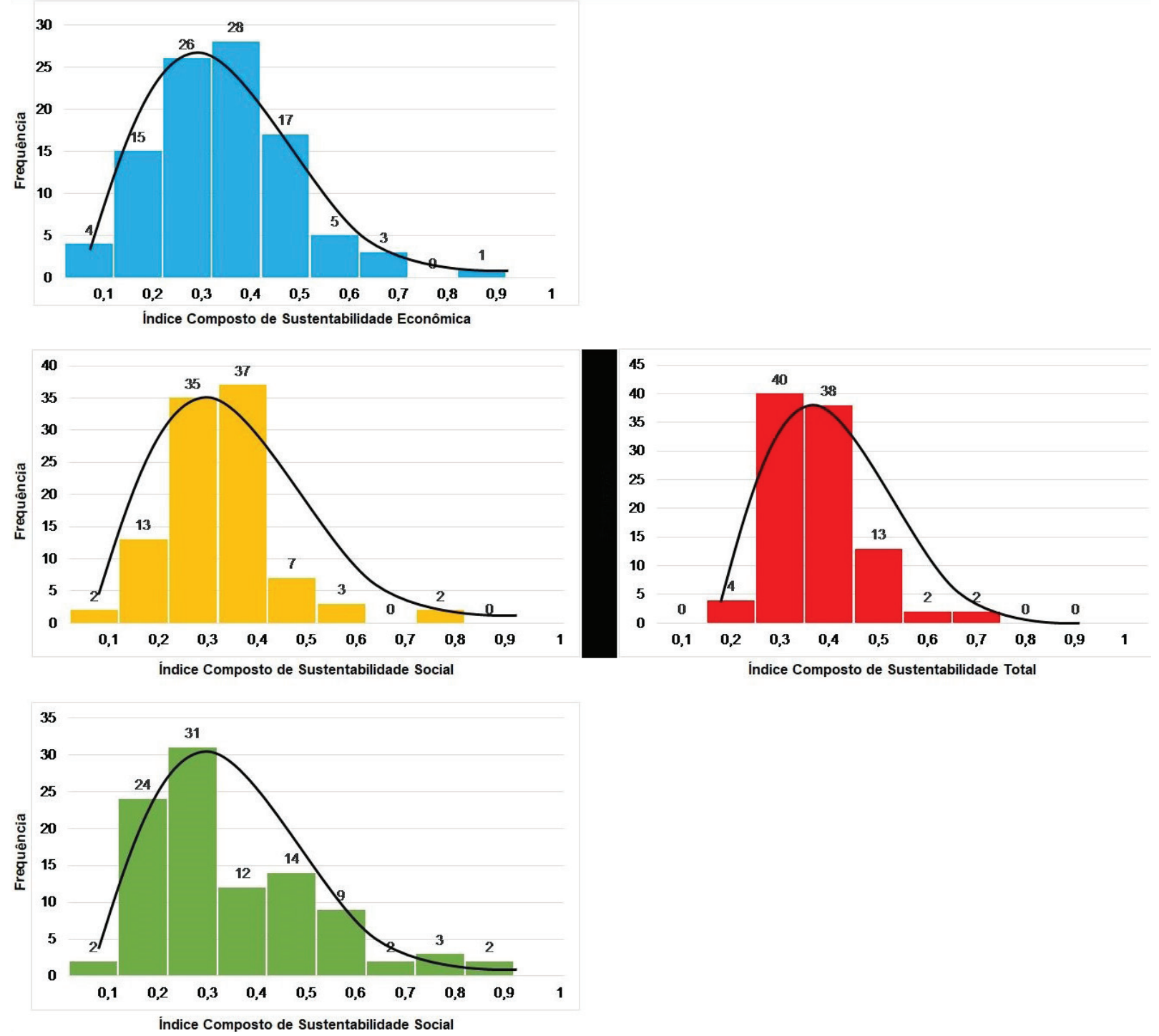

FIGURA 4 - Histograma de frequência dos índices compostos de sustentabilidade na Microrregião de Toledo Fonte: Elaborado pelos autores 
Seguindo a argumentação de Hazel et al. (2007), embora a regulamentação governamental através de leis deva ser a alternativa obvia para o enfrentamento destas questões, por vezes organizações locais podem ter papel relevante na intermediação e cooperação entre quem causa os danos ao meio ambiente e aqueles que são afetados por estes danos. A atuação de cooperativas e associações neste quesito pode ser feita através da conscientização, por meio de fóruns locais, ou mesmo com uma atuação junto aos órgãos governamentais, no sentido de se encontrar soluções que possam beneficiar ambas as partes, já que com frequência, estas situações podem envolver um grande número de pessoas separadas em termos de espaço, tempo e interesses.

Os resultados demonstrados na Figura 4 são compatíveis com os resultados apurados por Sulewski, Gajewska e Sroka (2018), que demonstraram haver um balanceamento nas três dimensões da sustentabilidade. Os autores classificaram as propriedades como tendo níveis baixos, médios ou altos de sustentabilidade, e constataram que, se uma propriedade obtivesse um nível médio, por exemplo, em uma dimensão, dificilmente obteria nível alto em outra, ou seja, concluíram que a maioria dos estabelecimentos agrícolas expressaram classificações similares nas três dimensões.

Se considerado o índice composto total, dois intervalos expõem frequências parecidas, sendo 40 produtores no intervalo e 38 produtores no intervalo . Somando-se as duas frequências, obtêm-se $86,7 \%$ do total da amostra.

Na Figura 4 também é possível se constatar que as linhas de distribuição, tanto nas três dimensões, como no índice composto total estão ajustadas mais à esquerda dos gráficos, indicando, como já salientado anteriormente, que os valores estão mais próximos de 0 do que de 1 , ou seja, estão mais longe do índice de sustentabilidade ideal e mais próximos do índice não ideal.

Um fato que pode ser verificado também nos histogramas de frequência, tanto das dimensões, quanto do índice composto total, é que o número de produtores com índices acima de 0,5 é reduzido. No índice geral, apenas quatro produtores apresentaram índice de sustentabilidade acima desse patamar. Nesse sentido, pelo critério do método TOPSIS, a grande maioria dos produtores de frutas, verduras e legumes da microrregião de Toledo, PR estão distantes da situação ideal de sustentabilidade, considerando os indicadores e os dados utilizados nesta pesquisa.

A análise tanto da Tabela 1, quanto das Figuras 3 e 4, também permitem sustentar que não há diferenças significativas entre as dimensões da sustentabilidade consideradas, ou seja, há uma similaridade entre as dimensões. Dessa forma, percebe-se que o nível de sustentabilidade dos produtores agrícolas, revelados pelos indicadores abordados na pesquisa, é relativamente próximo nos âmbitos econômico, social e ambiental.

Galdeano-Gómez et al. (2017), em estudo realizado na Espanha com sistemas agrícolas, após apurarem indicadores de sustentabilidade a nível dos estabelecimentos agrícolas, construíram índices agregados e verificaram o relacionamento entre as dimensões econômica, social e ambiental, concluíram haver melhorias nas dimensões econômica e social, diminuíam a pressão sobre os recursos ambientais. Além disso, observaram existir efeito positivo das dimensões social e ambiental para com a dimensão econômica. Estas são conclusões que estão de acordo com os resultados expressos no histograma da Figura 4, pois pode-se verificar, graficamente, haver forte relacionamento entre as três dimensões da sustentabilidade.

Após expor os resultados relativos aos indicadores simples e compostos de sustentabilidades, bem como fazer algumas discussões a respeito do nível de sustentabilidade dos produtores de frutas, verduras e legumes da microrregião de Toledo, PR, na próxima seção apresentamse as considerações finais do trabalho.

\section{CONSIDERAÇÕES FINAIS}

A partir do uso da metodologia TOPSIS foi possível agregar 16 indicadores simples de sustentabilidade, em três indicadores compostos de sustentabilidade, correspondentes as dimensões econômica, social e ambiental, e, também, um índice composto total de sustentabilidade para a microrregião.

A análise dos dados demonstrou que há similaridade entre os indicadores compostos das dimensões da sustentabilidade, podendo-se conjecturar, dessa forma, que o nível de sustentabilidade entre as dimensões não apresenta diferenças significantes.

Tanto os índices das dimensões, como o índice geral de sustentabilidade estão mais próximos de 0 do que de 1 , o que significa, de acordo com a metodologia TOPSIS adotada, que o nível de sustentabilidade dos produtores rurais da microrregião está mais distante de uma situação ideal de sustentabilidade e mais próximo de uma situação não ideal. Neste cenário, verifica-se a necessidade por parte dos agricultores, com o apoio dos governos locais, da adoção de estratégias comerciais que

Organizações Rurais \& Agroindustriais, Lavras, 22:e1515, 2020 
possibilitem o aumento no retorno financeiro da atividade, bem como maior relacionamento junto às instituições de ensino, pesquisa e extensão. Com isso, seria facilitada maior avanço na modernização tecnológica, e técnicas de cultivo e de gestão mais atualizados, que poderiam melhorar os resultados em termos de sustentabilidade nas três dimensões.

A metodologia adotada para a agregação e estruturação do índice composto se mostrou adequada, na medida em que facilita a visualização mais condensada e resumida do nível de sustentabilidade dos produtores rurais. Este é um fato explanado também por Xavier et al. (2018), que em proposta de indicador composto de sustentabilidade na agricultura em Portugal, comentam sobre o potencial destes indicadores em simplificar a análise e possibilitar comparações. A ponderação dos índices simples realizadas por meio da entropia, como deliberado pelo método TOPSIS, inclusive atenuou de forma satisfatória o potencial problema da atribuição de diferentes pesos aos critérios levantados por Areal et al. (2018), na medida em que esta atribuição não tem a intervenção do pesquisador.

Apesar disto, é necessário que se destaque algumas limitações do trabalho. Primeiramente, ressaltase que o objetivo da pesquisa era apenas aplicar uma metodologia de agregação de indicadores, criando um indicador composto de sustentabilidade, e que esta metodologia, ao ser aplicada na microrregião de estudo, demonstra a situação no momento da pesquisa. Assim, momentos diferentes, bem como, indicadores simples de sustentabilidade podem chegar a resultados também diferentes.

Como contribuições práticas da pesquisa podese citar os diagnósticos do nível de sustentabilidade na agrícola na microrregião analisada, bem como da aplicação prática de um método de agregação de indicadores, com objetivo de simplificar a análise. Como contribuição teórica, expande-se, por meio de um trabalho empírico, o arcabouço teórico sobre indicadores compostos de sustentabilidade na agricultura.

Por fim, sugere-se, para trabalhos futuros, a utilização da mesma metodologia de agregação de indicadores, inclusive com os mesmos indicadores simples, em outras regiões do Brasil, para que comparações possam ser realizadas. Além disso, pode-se analisar o nível de sustentabilidade de subgrupos dentro da amostra, que poderiam apresentar índices de sustentabilidade mais diferentes. É de se esperar, por exemplo, que produtores que possuem certificado de produtos orgânicos apresentem níveis mais altos de sustentabilidade.

\section{REFERÊNCIAS}

AREAL, F. J. et al. Measuring sustainable intensification: Combining composite indicators and efficiency analysis to account for positive externalities in cereal production. Land use policy, v. 75, p. 314-326, 2018.

BACHEV, H. Sustainability level of Bulgarian farms. Bulgarian Journal of Agricultural Science, v. 23, n. 1, p. 1-13, 2017.

BECKER, B. Sustainability assessment: A review of values, concepts, and methodological approaches. (Issues in Agriculture 10). Washington: Consultative Group on International Agriculture Research, 1997.

BINDER, C. R.; FEOLA, G.; STEINBERGER, J. K. Considering the normative, systemic and procedural dimensions in indicator-based sustainability assessments in agriculture. Environmental impact assessment review, v. 30, n. 2, p. 71-81, 2010.

CAVALCANTI, C. Sustentabilidade: mantra ou escolha moral? Uma abordagem ecológico-econômica. Estudos Avançados, v. 26, n. 74, p. 35-50, 2012.

ÇELEN, A. Comparative analysis of normalization procedures in TOPSIS method: with an application to Turkish deposit banking market. Informatica, v. 25, n. 2, p. 185-208, 2014.

CHAKRABORTY S.; YEH, C. H. A simulation comparison of normalization procedures for TOPSIS. In: 2009 International Conference on Computers \& Industrial Engineering (pp. 1815-1820). IEEE, 2009.

CHEN, F.; WANG, J.; DENG, Y. Road safety risk evaluation by means of improved entropy TOPSISRSR. Safety science, v. 79, p. 39-54, 2015.

COSTA, A. A.V. M. R. Agricultura sustentável III: Indicadores. Revista de Ciências Agrárias, v. 33, n. 2, p. 90-105, 2010.

DANTSIS, T. et. al. A methodological approach to assess and compare the sustainability level of agricultural plant production systems. Ecological indicators, v. 10, n. 2, p. 256-263, 2010. 
DE BOER, P. T.; KROESE, D. P.; RUBINSTEIN, R.Y. A tutorial on the cross-entropy method. Annals of Operations Research 134, p. 19-67, 2005.

DIAZ-BALTEIRO, L.; GONZÁLEZ-PACHÓN, J.; ROMERO, C. Measuring systems sustainability with multicriteria methods: A critical review. European Journal of Operational Research, v. 258, n. 2, p. 607-616, 2017.

EL GIBARI, S.; GÓMEZ, T.; RUIZ, F. Building composite indicators using multicriteria methods: a review. Journal of Business Economics, v. 89, n. 1, p. 1-24, 2019.

FALLAH-ALIPOUR, S. et al.. A framework for empirical assessment of agricultural sustainability: The case of Iran. Sustainability, v. 10, n. 12, 2018.

FAO. Sustainability Assessment of Food and Agriculture Systems: Guidelines 3.0. Rome, 2013.

FAO. Faostat domains: population. Disponivel em: $<$ http:// faostat3.fao.org/faostat-gateway/go/to/download/O/OA/ E>. Acesso em: 09 set. 2019.

FERRO-SOTO, C.; MILI, S. Desarollo rural e internacionalización mediante redes de Comércio Justo de café: um estudo de caso. Cuadernos de Desarollo Rural, v. 10, n. 72, p. 267-289, Bogotá, 2013.

GALDEANO-GÓMEZ, E. et al. Exploring synergies among agricultural sustainability dimensions: An empirical study on farming system in Almería (Southeast Spain). Ecological economics, v. 140, p. 99-109, 2017.

GRAY, R. M. Entropy and information theory. Springer, 2011.

GUEDES, A. C.; TORRES, D. A. P.; CAMPOS, S. K. Sustentabilidade e sustentação da produção de alimentos e o papel do Brasil no contexto global. In: BUAINAIN, A.et al. (Editores técnicos). O mundo rural no Brasil do século 21: a formação de um novo padrão agrário e agrícola. Brasília: Embrapa, 2014.

HAFEZALKOTOB, A.; HAFEZALKOTOB, A. Extended MULTIMOORA method based on Shannon entropy weight for materials selection. Journal of Industrial Engineering International, v. 12, n. 1, p. 1-13, 2016.
HAQ, S.; BOZ, I. Measuring environmental, economic, and social sustainability index of tea farms in Rize Province, Turkey. Environment, Development and Sustainability, v. 22, n. 3, p. 2545-2567, 2020.

HAYATI, D.; RANJBAR, Z.; KARAMI, E. Measuring agricultural sustainability. In: LICHTFOUSE, E. (ed). Biodiversity, Biofuels, Agroforestry and Conservation Agriculture, Sustainable Agriculture Reviews. Springer, 2010 .

HAYATI, D. A literature review on frameworks and methods for measuring and monitoring 639 sustainable agriculture. Technical Report n. 22, Global Strategy Technical Report. Rome, 2017.

HAWKSWORTH, J.; CHAN, D. World in 2050: the BRICs and beyond: prospects, challenges and opportunities. London: Price water house Coopers, 2013. 25 p. (PwC Economics). Disponível em: $<$ https:// www.pwc.com/en_GX/gx/world-2050/assets/pwcworld-in-2050-report-january-2013.pdf $>$. Acesso em: 09 set. 2019.

HAZELL, P. et al. Development strategies for less-favored areas. In: BULT, E.; RUBEN, R. (eds.). Development Economics between Markets and Institutions: Incentives for Growth, Food Security and Sustainable Use of the. Mansholt Publication Series - v. 4. Wageningen Academic Publishers, 2007.

HWANG, C. L.; YOON, K. Multiple attribute decision making: methods and applications. New York: Springer, 1981.

IBGE - INSTITUTO BRASILEIRO DE GEOGRAFIA E ESTATÍSTICA. Projeção da população do Brasil por sexo e idade: 2000-2060. 2013. Disponível em: <http:// www.ibge.gov.br/home/estatistica/populacao/projecao_da populacao/2013/default.shtm>. Acesso em: 09 set. 2019.

JRC-EC - JOINT RESEARCH CENTRE-EUROPEAN COMMISSION. Handbook on constructing composite indicators: methodology and user guide. OECD publishing, 2008.

KAHRAMAN, C. (Org.) Fuzzy multicriteria decision making: theory and applications with recent developments. Turkey: Springer Science, 2008. 
KELLY, E.. Sustainability indicators for improved assessment of the effects of agricultural policy across the EU: Is FADN the answer?. Ecological indicators, n. 89, p. 903-911, 2018.

LATRUFFE, L.; DESJEUX, Y. Common Agricultural Policy support, technical efficiency and productivity 666 change in French agriculture. Review of Agricultural, Food and Environmental Review, n. 97, v. 1, p. 15-28, 2016.

LATRUFFE, L. et al. Measurement of sustainability in agriculture: a review of indicators. Studies in Agricultural Economics, n. 118, v. 3, p. 123-130, 2016.

LÓPEZ-RIDAURA, S.; MASERA, O.; ASTIER, M. Evaluation the sustainability of complex socioenvironmental systems. The MESMIS framework. Ecological Indicators, n. 2, p. 135-148, 2002.

LUTZ, W.; SANDERSON, W.; SCHERBOV, S. The end of world population growth. Nature, London, n. 412, p. 543-545, 2001.

McCOOL, S. F.; STANKEY, G. H. Indicators of sustainability: challenges and opportunities at the interface of science and policy. Environmental management, $\mathrm{n}$. 33, v. 3, p. 294-305, 2004.

MELO, R. B. A certificação Fairtrade no setor exportador de frutas frescas no Brasil. 218p. Tese Centro de Estudos e Pesquisas em Agronegócios, Programa de Pós-Graduação em Agronegócios, Universidade Federal do Rio Grande do Sul, 2015.

MOHAN, S. Fair trade without the froth: a dispassionate economic analysis of 'fair trade'. London: The Institute of Economic Affairs, 2010.

MUNDLER, P. Petites Exploitations Diversifiées en Circuits Courts. Soutenabilité Sociale et Économique. ISARA Lyon, 2008.

MÜLLER, S. Como medir la sostenibilidad? Una propuesta para el area de la agricultura y de los recursos naturales. IICA/BMZ/GTZ, Costa Rica, 55 p. Série Documentos de Discusión sobre Agricultura Sostenible y Recursos Naturales, n.1, 1996.
NGODUY, D.; MAHER, M. J. Calibration of second order traffic models using continuous cross entropy method. Transportation Research Part C: Emerging Technologies, v. 24, p. 102-121, 2012.

OLIVEIRA, R. F.; ARAÚJO, U. P.; SANTOS, A. C. Efeito do fair trade na cooperativa de agricultores familiares de café de Poço Fundo. Organizações Rurais \& Agroindustriais, Lavras, v. 10, n. 2, p. 211-225, 2008.

PARRIS, T. M.; KATES, R. W. Characterizing and measuring sustainable development. Annual Review of Environment and Resources, n. 28, p. 559-586, 2003.

QUIRINO, T. R. et al. Ambiente, sustentabilidade e pesquisa: tendências da agricultura brasileira até 2005 . Empresa Brasileira de Pesquisa Agropecuária. Centro Nacional de Pesquisa de Monitoramento e Avaliação de Impacto Ambiental. Campinas: EMBRAPA - CNPMA, 1997.

RASUL G.; THAPA, G. B. Sustainability analysis of ecological and conventional agricultural systems in Bangladesh. World Dev. v. 31, n. 10, p. 1721-1741, 2003.

REIFSCHNEIDER, F. J. B.; LOPES, C. A. Horticultura brasileira sustentável: sonho eterno ou possibilidade futura? Revista de Política Agrí́cola, ano XXIV, n. 2, abr./jun. 2015.

SCANDAR NETO, W. J. Síntese que organiza o olhar: uma proposta para construção e representação de indicadores de desenvolvimento sustentável e sua aplicação para os municípios fluminenses. Dissertação de Mestrado, Escola Nacional de Ciências Estatísticas, Rio de Janeiro, 2006, 119p.

SCHNEIDER, J. Relatório da Pesquisa Mundial de Comércio Justo: parte 1. Brasília: SEBRAE, 2012.

SOUZA FILHO, H. M. Desenvolvimento agrícola sustentável. In: BATALHA, M. O. (coordenador). Gestão agroindustrial. 3. Ed. São Paulo: Atlas, 2012.

SULEWSKI, P.; KłOCZKI-GAJEWSKA, A.; SROKA, W. Relations between agri-environmental, economic and social dimensions of farms' sustainability. Sustainability, v. 10, n. 12, p. $4629,2018$. 
XAVIER, A. et al. A regional composite indicator for analysing agricultural sustainability in Portugal: A goal programming approach. Ecological Indicators, v. 89, p. 84-100, 2018.

WANG, Q.; DAI, H. N.; WANG, H. A smart MCDM framework to evaluate the impact of air pollution on city sustainability: A case study from China. Sustainability, v. 9, n. 6, p. 911, 2017.

WIRÉN-LEHRS, S. von. Sustainability in agriculture: an evaluation of principal goal-oriented concepts to close the gap between theory and practice. Agric Ecosyst Environ, v. 84, p. 115-129, 2001. 